\title{
Ice sheet-climate interactions during the ice age cycle
}

Ayako Abe-Ouchi ${ }^{1}$ and Bette Otto-Bliesner ${ }^{2}$

1University of Tokyo, Japan; abeouchi@ccsr.u-tokyo.ac.jp; ${ }^{2}$ National Center for Atmospheric Research, Boulder, USA; ottobli@ucar.edu

\section{The impact of ice sheet size and geometry on both climate and the ice sheet itself is investigated with general circulation models. This information is used to simulate the observed change of ice sheet and sea level throughout the ice age cycle.}

Large ice sheets influence climate through changes in surface albedo, land and ocean temperature, atmosphere and ocean circulation, and other feedbacks in the climate system. The climate in turn drives ice sheet growth or retreat and thus drives changes in sea level. To estimate ice sheet and sea level change, it is crucial to evaluate these ice sheet-climate interactions (Clark et al., 1999). To simulate ice sheet evolution, past climateforcings are needed, and to simulate climate, an ice sheet shape (topographical distribution) is needed as a boundary condition. Future climate and sea level changes are being estimated using a combina- tion of general circulation models (GCMs) and ice sheet models. It is important to evaluate the ability of these models by performing paleoclimate experiments and validating them with paleoclimate data. It is, however, not an easy task because both the data and models are still far from perfect and contain many uncertainties. Moreover, computation of long timescales (tens of thousands of years or more) is not easy with a GCM. So far, two types of modeling efforts exist that are aimed at understanding the ice sheet-climate coupling process. Here, we discuss progress in these two approaches. One is the study of the response

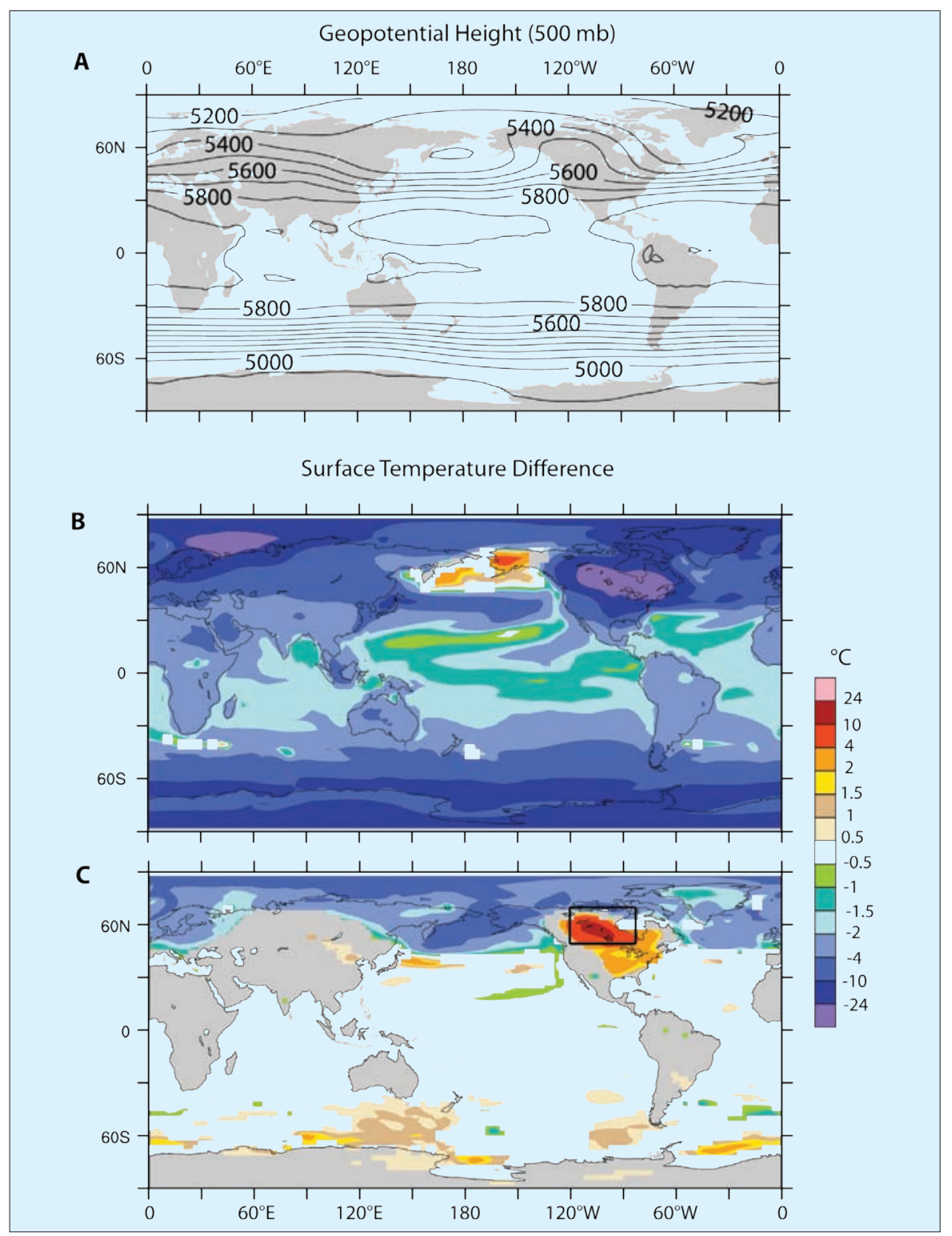

Figure 1: $\boldsymbol{A})$ Mean annual 500-mb geopotential height $(m)$ for the LGM simulation with ICE5G reconstruction; B) Annual surface temperature difference $\left({ }^{\circ} \mathrm{C}\right)$ for the LGM simulation with ICE5G reconstruction compared to a preindustrial simulation; C) Annual surface temperature difference $\left({ }^{\circ} \mathrm{C}\right)$ of $L G M$ simulations with reduced ice sheet topography (blackbox) minus regular (ICE5G) LGM simulation; only differences significant at 95\% are shown (Figure modified from Otto-Bliesner et al., 2006). of climate to a fixed ice sheet boundary condition, and the other is the study of the ice sheet evolution under climate forcing driven by information obtained from GCM experiments.

\section{Climate response to ice sheets}

The GCMs used for future projections have also been applied to the Last Glacial Maximum (LGM, ca. $21 \mathrm{ka}$ ), when the most recent large-scale ice sheets existed. These GCMs typically use a spatial resolution of $3-5^{\circ}$ in latitude and longitude to allow a number of sensitivity studies, although higher resolution GCMs with about 1 deg resolution in latitude and longitude are also being used for focused experiments to resolve the topographical and geographical boundary conditions of realistic ice sheets (Yamagishi et al., 2005; Jost et al., 2005; Abe-Ouchi et al., 2007). The most common experimental design for LGM experiments is to incorporate the boundary conditions different from present day for: 1) orbital parameters (Berger, 1978), 2) atmospheric greenhouse gas content (e.g., $\mathrm{CO}_{2}$ from ice cores), and 3) reconstructed global ice sheet topography (PMIP; Paleoclimate Modelling Intercomparison Project, Bracconot et al., 2007). Fortunately, the geographical distributions of the ice sheets are well documented for the maximum extent at the LGM and for the deglaciation phase (21-0 ka), while the thickness must be estimated by modeling. In the 1980s, the ice sheet reconstruction by the CLIMAP project assumed a parabolic ice sheet shape (CLIMAP, 1981), and for the last 15 years, global ice sheets were reconstructed using the geodynamical models ICE4G (Peltier, 1994) and ICE5G (Peltier, 2004). The ICE4G and ICE5G reconstructions differ in the spatial extent, height and volume of the ice sheets at the LGM. In ICE5G, the Laurentide Ice Sheet over North America contains significantly more volume than ICE4G, with the Keewatin Dome west of Hudson Bay 2-3 km higher over a broad area of central Canada. Further, in ICE5G the Fennoscandian Ice Sheet does not extend as far eastward into northwestern Siberia as it did in ICE4G.

Atmospheric GCM experiments have been performed with and without LGM ice sheets as a boundary condition. It has been shown that ice sheets at the LGM 
play a big role in modifying the westerly wind and surface pressure distribution, and in cooling the climate in the Northern Hemisphere, especially in mid- to high -latitudes (Rind, 1987; Manabe and Broccoli, 1985; Broccoli and Manabe, 1987; Felzer et al., 1996). The impact of ice sheets on atmospheric circulation is characterized by a stronger anticyclone over the ice sheet, a stronger trough and cold air over the east side of North America, a sharper storm track in the North Atlantic, and more precipitation in the southern periphery of the Laurentide Ice Sheet. Moreover, the impact is shown to be important not only in the North Atlantic but also in the North Pacific. The height of the Laurentide Ice Sheet has been shown to be important in these responses. The results of a sensitivity experiment replacing the high dome of the ICE5G Laurentide Ice Sheet with ICE4G heights from $50-70^{\circ} \mathrm{N}$, and $85-120^{\circ} \mathrm{W}$ and keeping the ICE5G heights elsewhere are shown in Figure 1 (Otto-Bliesner et al., 2006). Lowering of the high dome leads to less upper-air ridging and significant cooling both upstream and downstream of North America.

\section{Ice sheet evolution under climate forcing}

Ice sheet models can provide the time sequence of ice sheet shapes (area and topography) using ice sheet flow and thermo-mechanical coupling, as well as sliding and basal deformation (Marshall, 2005). For the climatic forcing to drive these ice sheet models, most models interpolate the monthly mean temperatures estimated from GCM simulations for LGM and pre-industrial time slices, and are weighted by the time sequence of isotopic temperature derived from Greenland ice cores (Charbit et al., 2007; Zweck and Huybrechts, 2005; Marshall and Clark, 2002; Tarasov and Peltier, 2004). These temperature and precipitation fields, together with the altitude effect according to a certain lapse rate (the temperature change per given altitude change), are given as the "forcing" to the ice sheet model. However, with this method the impact of astronomical forcing upon the change of seasonal insolation, which is key for ice age cycles in the Milankovitch theory (Milankovitch, 1930), is not taken into account. In these studies, the gravitational load of a thickening ice sheet in an LGM-run indirectly forces the fast spread of the ice, and results in formation of a flat ice sheet before it can reach the size of an IGE5G LGM ice sheet. On the other hand, the model setup limits the expansion of the ice sheets to the reconstructed LGM ice sheet extent.

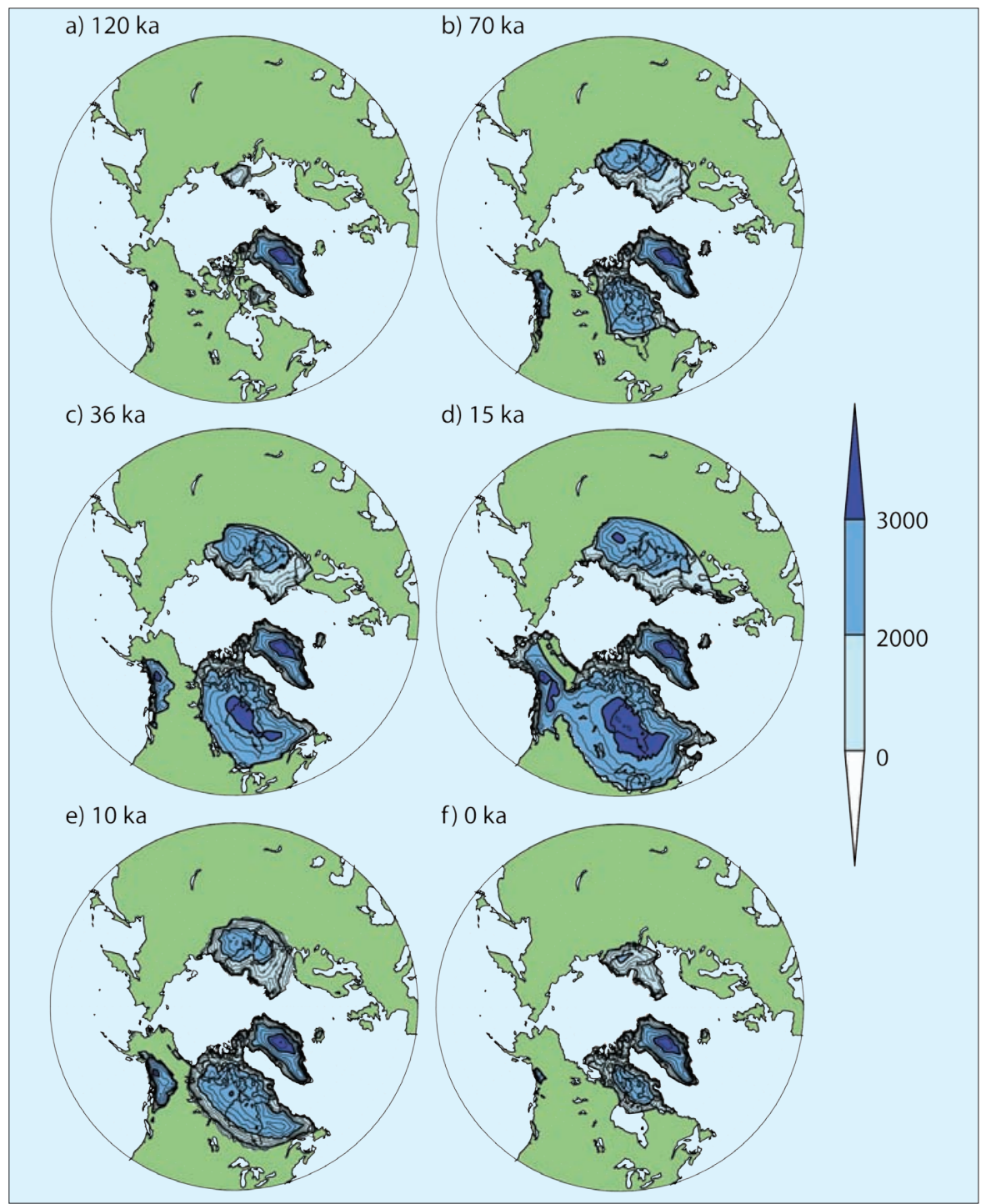

Figure 2: Simulated N. Hemisphere ice sheet distribution at different time slices. Contour intervals are $250 \mathrm{~m}$ (thin lines) and $1000 \mathrm{~m}$ (thick lines, blue shading). The approx. volume of each ice sheet in terms of sea level contribution is a) $-6 m, b)-52 m, c)-90 m, d)-138 m, e)-77 m, f)-27 m$. Figure modified from Abe-Ouchi et al. (2007).

To overcome this problem, an alternative method of forcing the ice sheet model has been proposed (Abe-Ouchi et al., 2007). Initially, several GCM experiments with different $\mathrm{CO}_{2}$ levels, orbital forcing and ice sheet size and height are carried out, to include the effects for driving ice sheets separately. In addition, the lapse rate for the ice sheet evolution can be estimated from these simulations, and it is found to be a smaller value than in many studies but is consistent with a study on the Antarctic Ice Sheet (Krinner and Genthon, 1999). When this information is used to drive a dynamical ice sheet model with the time series of $\mathrm{CO}_{2}$ from ice cores (Petit et al., 1999) and the insolation of Berger (1978), the ice sheet expansion and retreat are successfully simulated throughout the ice age cycle, as in Figure 2. The thickest part of the Laurentide Ice Sheet is in the eastern part of Canada near Hudson Bay and an ice-free part appears in Alaska, which is consistent with observations. Studies are on-going to improve model representation of basal processes and ice shelf/ice stream processes to obtain a thinner ice sheet over Eurasia.

Once the model successfully simulates ice sheet expansion and retreat, the causes and mechanisms of ice age cycles will be investigated in more detail with many sensitivity studies. Moreover, modeling is expected to enable studies linking past change to projections for the future.

\section{References}

Abe-Ouchi, A., Segawa, S. and Saito, F., 2007: Climatic Conditions for modelling the Northern Hemisphere ice sheets throughout the ice age cycle, Climate of the Past, 3: 423-438.

Braconnot, P. et al., 2007: Results of PMIP2 coupled simulations of the mid-Holocene and Last Glacial Maximum Part 1: experiments and large-scale features, Climate of the Past, 3: 261-277.

Marshall, S.J., 2005: Recent advances in understanding ice sheet dynamics, Earth and Planetary Science Letters, 240: 191-204.

Otto-Bliesner, B.L, Brady, E.C., Clauzet, G., Tomas, R., Levis, S. and Kothavala, Z., 2006: Last Glacial Maximum and Holocene Climate in CCSM3, Journal of Climate, 19: 2526-2544.

Yamagishi, T., Abe-Ouchi, A., Saito, F., Segawa, T. and Nishimura, T., 2005 Re-evaluation of paleo-accumulation parameterization over Northern Hemisphere ice sheets during the ice age examined with a high-resolution AGCM and a 3-D ice-sheet model, Annals of Glaciology, 42: 433-440.

For full references please consult:

www.pages-igbp.org/products/newsletters/ref2009_2.html 